\title{
ITINERARIOS MERCANTILES Y EXPLOTACIÓN DEL CAUCHO-SHIRINGA EN EL SUR-ORIENTE DEL PERÚ*
}

\author{
Óscar Paredes Pando
}

\section{RESUMEN}

Cuando llegué por vez primera a Puerto Maldonado, en agosto de 1978, pensé que todos los inmigrantes habían llegado a aquella ciudad, por la ruta Ocongate-Quincemil. Tremendo desacierto. Fue don Emilio Manrique Apaza (Q.E.P.D.), humilde conserje del Comité de Desarrollo de Madre de Dios-CODEMA, en una conversación fortuita, quien me dijo que había llegado a inicios de 1940, adolescente aún, por la ruta Carabaya-Inambari, viajando durante dos semanas junto a los arrieros y desde Tirapata- Azángaro.

Aquel aleccionador diálogo hizo que empezara a corregir mis discursos tecnoburocráticos, gran parte de ellos aprendidos en el Instituto Nacional de PlanificaciónINP, donde los funcionarios haciamos coro a la imaginada Región Sur-Oriente: Apurímac, Cusco y Madre de Dios, que no pasaba de ser una sumatoria de jurisdicciones administrativas, ajenas a procesos sociales generalmente desconocidos, debido a la carencia de investigaciones y, por tal motivo, gran parte de las propuestas sobre desarrollo regional fracasan.

De modo que a partir del diálogo con el Tío Manrique -como llamábamos respetuosa y cariñosamente al inmigrante octogenario-, empecé a conocer y entender que décadas atrás la relación Puno-Madre de Dios fue bastante fluida y el ámbito Carabaya -Tambopata la mejor expresión del continum Andes-Amazonía, asunto que traté con rigurosidad en mi segunda tesis doctoral (2011).

Habíamos olvidado que desde hace quinientos años diversos espacios sociales fueron desestructurados y fragmentados: uno de ellos, el eje Carabaya -Tambopata prácticamente desapareció durante tres siglos hasta que fue reactivado aproximadamente durante las primeras cuatro décadas del s. XX por el extractivismo cauchero - siringuero (Castilloa elástica-Hevea brasiliensis). Exploradores, aventureros y arrieros, tras las huellas dejadas por las poblaciones de las partes altas y de las partes bajas, ingresaban a los bosques, que más adelante modelaron verdaderos itinerarios mercantiles, desapareciendo nuevamente con la crisis de aquellas economias, pero que hoy se va reactivando con la Vía Interoceánica, en cuyos primeros estudios participamos a inicios de 1980. 
A partir de la vía Interoceánica, en estos tiempos asistimos a un nuevo proceso de reterritorialización, hecho que tendrá efectos directos en la esperada descentralización y regionalización, lo cual no es asunto administrativo como quiere entenderse. De esta manera, el Sur del Perú durante las próximas décadas puede inclusive retomar su forma de organización territorial anterior al s. XVI y que fue el resultado de procesos que llevaron algunos miles de años a los pueblos de las partes altas, Ayaziris, Lupaqas; de las partes intermedias, Kallawayas; y de las partes bajas, Yamiacas y Ese-ejas del Eori-Bawaja. (Paredes Pando, O. 2009).

Sobre aquellas relaciones pueblos de arriba y pueblos de abajo o Altiplano-Amazonía, el mismo Plan Regional del Sur o Plan del Sur (1959), señalaba:

"La ceja de montaña $[. .$.$] esta es una región muy$ extensa y de una población bastante esparcida. Sandia es la puerta de entrada al área de producción de café llamada San Juan del Oro, no hace poco convertida en distrito.

Ollachea, que recientemente ha sido unida a Macusani por un camino, es una puerta similar hacia Inambari, y la región de agricultura semi tropical [...] Si bien todavía es parte de la ecología serrana, se caracteriza por su comercio con la selva [...] Algunas de las tradiciones más antiguas en cuanto a la organización social y aún en la cultura material están presentes en los pueblos de la ceja de selva mientras han desaparecido en otras áreas más tradicionales de la sierra [...] En Ayapata existe un ciclo anual triple de actividades agrícolas, a base de cultivos de coca, maíz y tubérculos [...]" (El subrayado es nuestro).

Luego de tres siglos de olvido de la Amazonía, el extractivismo mercantil de las gomas elásticas tratando de atender las demandas internacionales, puso en el escenario a dicha ecorregión de bosques siempre verdes e hiperhúmedos, donde el caucho y la siringa encontraron su destino en los mercados de Estados Unidos de Norte América y Europa.

Así, la Amazonia ingresaba en esta nueva dinámica con sus bosques, sistema hidrográfico y mano de obra gratuita de las poblaciones étnicas. Transcurrido el ciclo económico caucheroshiringuero quedó el recuerdo de los años dorados, millones de árboles talados y, sobre todo, la destribalizaciòn étnica; además los recuerdos de los itinerarios mercantiles que con el presente estudio tratamos de refrescar el olvido de la reciente historia social y espacial.
Los procesos de acumulación, dada a partir de aquellas explotaciones caucheras, advirtieron a los estados que comparten la Gran Amazonía: Brasil, Bolivia, Colombia, Ecuador y Perú que tales territorios empezaban a valorizarse; además, muchas de aquellas regiones tenían una importancia geopolítica y geoestratégica y como tal, cada Estado, sentía la necesidad de consolidar sus respectivas soberanías. Fueron tiempos de definición de las actuales fronteras, como cuando perdimos Leticia frente a Colombia, el PurúsAcre, frente a Brasil, y también territorios de Madre de Dios, frente a Bolivia, cuyos caucheros habían ingresado hasta el actual río Inambari.

Cada país empezó -Brasil lo hizo desde el s. XVI- a diseñar sus propias estrategias. El Perú se proponía integrar fisicamente la región de los bosques, territorios que habían sido parte de la soberanía del Tawantinsuyu hasta las nacientes del río Madera o Madeira, en la desembocadura del río Beni (Pärssinen, M. A. Siiriäinen, 2008), llegando posiblemente a navegar en el mismo río Amazonas. Una relectura de las crónicas de Gaspar de Carvajal (1541) y Cristóbal de Acuña (1640) son suficientes para entender aquellos procesos. Por tal razón, el Plenipotenciario Víctor M. Maúrtua (1906) - con la participación activa del Bibliotecario de la UNSAAC Juan Pablo Villanueva- tomó aquellas crónicas como base y juntamente con otros documentos organizó un expediente de dieciocho tomos -que hoy no se sabe dónde se encuentranpara la defensa de la soberanía durante aquel diferendo con Bolivia a inicios del s. XX y cuyo arbitraje correspondió al gobierno argentino.

Dentro de aquellas estrategias por consolidar soberanías en territorios desconocidos, o territorios de las Naciones de Chunchos, el Perú optó por la infraestructura de transporte y comunicaciones: caminos, correos y telégrafos. Para lo cual, hace un siglo, optó por las concesiones o contratos con terceros -hoy conocido como privatización-, a cambio de grandes áreas boscosas para su explotación principalmente cauchero-shiringuera y para tal efecto, el gobierno formalizó una serie de contratos y también promovió algunas expediciones, siendo las más representativas para la región suroriental, las siguientes:

\section{A. Estado Peruano - Societé Anonyme Industrialle et Financiere de l'Ameriqué du Sud}

Contrato formalizado mediante Resolución del 19 de abril de 1901. La Societé, estuvo 
representada por don Emilio José del Valle; el propósito fue la construcción de caminos desde los Andes hasta la confluencia de los ríos Inambari, por una parte y por otra, hasta Pilcopata-Alto Madre de Dios a través de Challabamba hacia Aqanaku-Tres Cruces. Esta ruta está asociada al gran Apu Kañaqway, sobre el que Joan de Santa Cruz Pachacuti Yanqui Salcamaygua (1613), registró el siguiente relato:

"Dizen que por consejo de su Huaca Cañacuay lo querían matar al dicho Ynga. Y entonçes nació su hijo segundo, Topa Ynga Yupanqui. Al fin, el dicho Pachacuti Ynga Yupanqui haze la entrada y conquista de los Andesuyos con çien mil hombres. Y entonces la Huaca de Cañacuay se arde fuego temerario y no les consiente pasar la gente. $Y$ al cabo se apareçe temeraria culebra, el cual dicen que consumió mucha gente, de que él abía tenido gran pena y se aflexe y alsa los ojos al cielo, pediendo socorro al Señor del cielo y tierra con gran aflexçión y llanto. $\mathrm{Y}$ entonçes biene del cielo una aucancana o águila con una furia temeraria, dando grandes zumbidos y arrebata a la culibra, y alssa al alto de la cabeça, y después la dexa caer al suelo. Y dizen que se reventó, y otra su compañera lo mismo abía reventado [...]"

La Societé, con sede en París, luego del contrato transfirió dichas obligaciones a la Societé Pacifiqué Amazoné, de capitales italianos. En aquella negociación, tuvo un papel protagónico el Dr. Francisco García Calderón, representante de la Societè, pues había recibido amplios poderes mediante Escritura Pública hecha en la ciudad de Sicuani, Cusco, el 22 de abril de 1902). La nueva Societé, además de abrir un camino de herradura, tenía el propósito de poner en marcha la inmigración y colonización Italiana en el Perú. Señalaba su Estatuto:

"Art. 1'. La Sociedad de Inmigración y Colonización Italiana en el Perú es una institución que se establece con el objeto de promover y fomentar la inmigración organizada de italianos en el Perú. Su duración será indefinida"

(Lima, 20 de julio de 1905. AGN-OPP).

Asimismo, la Societè ofrecía un conjunto de beneficios para los inmigrantes, como

- Pasajes cubiertos por el gobierno peruano.

- Garantía de ocupación de tierras y bosques.

- Promoción de industrias con facilidades en cuanto a exoneraciones sobre impuestos, etc.

Estasinquietudes de integraryocuparla Amazonía fueron bien recibida por otras representaciones diplomáticas; así, el Cónsul General de Viena, enviaba una nota al gobierno peruano señalando:
"Un agricultor de Bohemia, de nombre Tomas Otruba, ha manifestado a esta Oficina tener intención de emigrar al Perú para dedicarse allí a la agricultura. Añade que tres de sus yernos, agricultores como él, tienen el mismo propósito de establecerse en el Perú $[\ldots$. ]"

(M. Relaciones Exteriores, 1911).

\section{B. Expedición Marcapata - Madre de Dios}

Promovida por el senador por Loreto don Enrique S. Llosa -antes encargado de la agrimensura en Madre de Dios- y que tuvo por principal objetivo buscar una ruta directa desde la provincia de Quispicanchis hacia las montañas del Inambari-Madre de Dios. Enrique Llosa, desconocía -y muchos desconocemos- que uno de los Hatun $\tilde{N} a n$ de los inkas hacia los Antis, precisamente ingresaba a la cuenca del río Araza a través del abra de Walla walla, donde durante la construcción de la carretera -década de 1960- se encontraron idolillos en oro y plata, posiblemente asociadas a prácticas culturales en función del Apu Ausanqati y a todo aquello que significó Qoyllor Rit'i.

La expedición de Enrique Llosa se inició el 6 de mayo de 1906, pasando por la hacienda Cadena, propiedad de Juan Kalinowski, en el valle de Marcapata. Los expedicionarios se dirigieron por el río Nusiniscato hacia el río Punquiri, continuando por sus orillas hasta antes del río Karene y del Colorado, lugar al que denominaron Puerto Deseado, donde se embarcaron en balsas y canoas para continuar hasta el río Madre de Dios. Los expedicionarios se instalaron frente a la desembocadura del río Colorado, bautizando dicho lugar con el nombre de Tawantinsuyu; de este punto, sus compañeros retornaron a Marcapata, en tanto que Llosa continuó hacia Puerto Maldonado, retornando por la ruta Tambopata-Carabaya hacia el altiplano puneño.

Los informes de esta expedición fueron los referentes en la construcción de la vía Ocongate-Quincemil-Puente Inambari; asimismo, en la construcción de la trocha Sicuani-Santa Bárbara-Marcapata, llevada a cabo en la década de 1940.

\section{Contrato Estado Peruano-Chester W. Browmn}

Luego de la disminución en el s. XVIII de los placeres auríferos en el Alto Tambopata, Inambari y Marcapata, los nuevos hallazgos 
en Camantí hacia 1840 hicieron que la minería aurífera resurgiera; esta tendencia continuó por la zona del río Wari wari, y en 1896 la familia Estrada Velasco reorientó sus minas de Santo Domingo, formalizando la venta de sus denuncios en 1901 .

La prensa limeña sobre el oro aluvial de aquella región informaba en los siguientes términos:

"En el río Chilimayo, afluente del Inambari se descubrió una gran riqueza aurífera, se extrae oro grueso y en abundancia. Hemos visto en poder del señor Téfilo Velasco una pepita de 1 libra y 16 onzas de peso y sabemos que descubrió otra de doble peso hace algunos meses, y que hoy indebidamente está en manos del antiguo subprefecto de Carabaya, señor S. Zamalloa.

Indudablemente el oro tiene ciertas preferencias por la familia Velasco, pues ese caballero es sobrino del antiguo dueño de la mina Santo Domingo.

("El Comercio", Lima, setiembre de 1900. El subrayado es nuestro].

Estas noticias empezaron a motivar a los exploradores y aventureros. Entre ellos, a Chester W: Brown, ciudadano de origen estadounidense con experiencia en minería aurífera en la región de California, quien en 1902 compró los denuncios a la familia Estrada Velasco, dando origen a la "Inca Mining \& Co. USA", que durante el s. XX, llegó a ser la primera empresa productora de oro en el Perú, justamente en tiempos en que se adoptaba el oro como patrón de la moneda.

Chester Browmn organizó la Inca Rubber Co. con la finalidad de explotar caucho-shiringa tratando de ingresar a la Amazonía por el Alto Inambari y Tambopata; para el efecto dio inicio a la reapertura de caminos. Desde luego, antes había llegado a acuerdos con el Estado peruano para dotar de una trocha desde la mina Santo Domingo hasta un punto navegable en el río Tambopata y así acceder a la región Madre de Dios.

Aquel contrato fue sancionado por Resolución Suprema del 16 de mayo de 1902; asimismo, el 4 de diciembre de 1903 se reconoció a la Inca Rubber Co. como concesionaria del camino a construirse; de igual manera, mediante R. S. del 29 de mayo de 1908 , se formalizó la entrega de tres lotes de la montaña a la Inca Rubber en compensación por la construcción del camino a construirse o reabrirse.

En realidad los títulos de propiedad de las concesiones obtenidas por la Inca Rubber Co. datan de 1902, con la siguiente descripción:

\section{(2)}

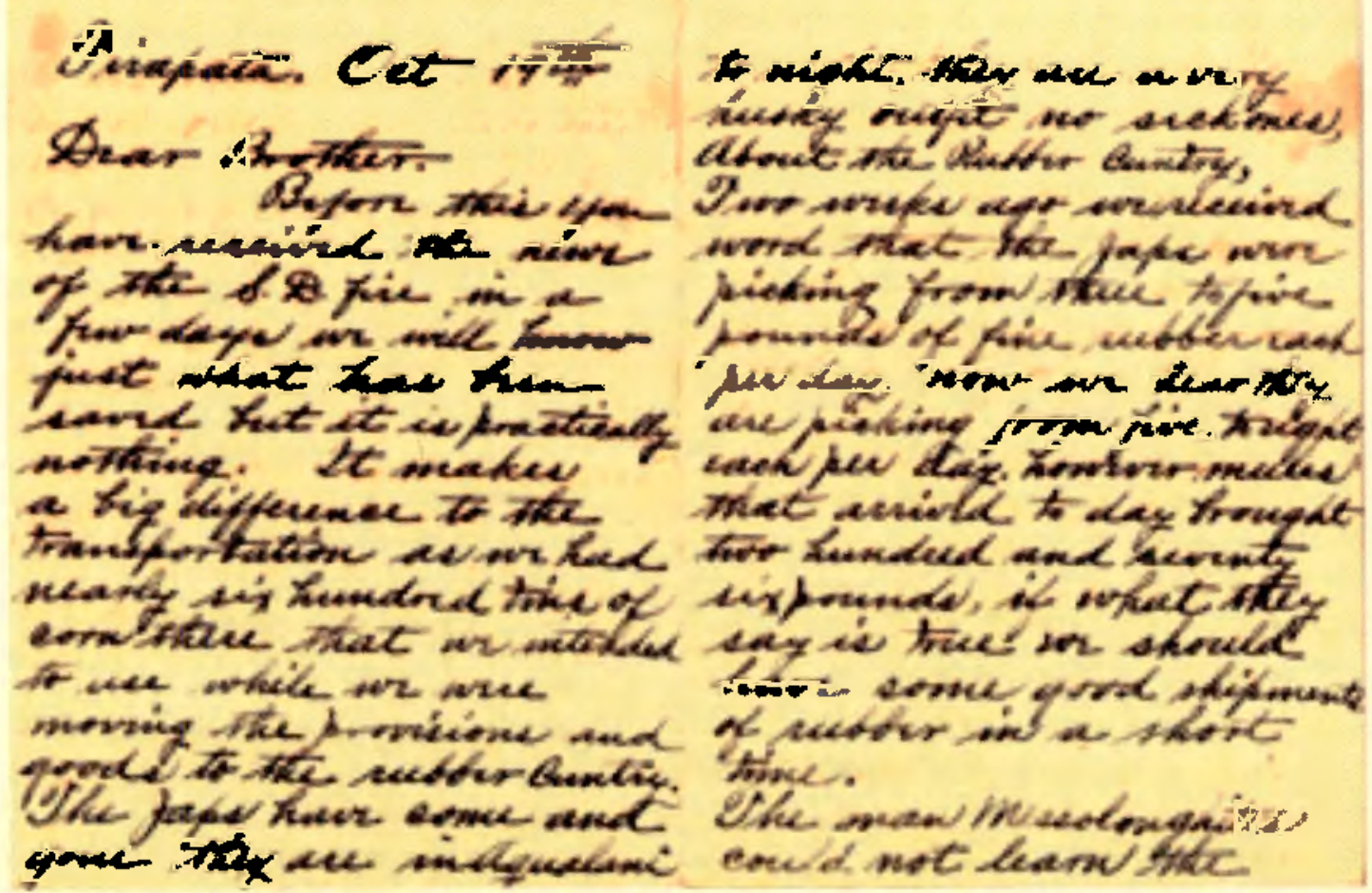

Correspondedenctas de Chester W. Broumn 
"El primero de 244,460 hectáreas, siendo sus límites por el $\mathrm{N}$. una línea paralela a la margen derecha del río Madre de Dios y el paralelo 13 grados, y por el E. una recta que forma el curso medio del río Heath y por el $\mathrm{O}$. una línea paralela a la margen derecha del río Tambopata y distante de ella 50 metros.

El Segundo lote de 10,540 has. Se extiende a lo largo y a ambos lados del camino de herradura construido por la misma Cía. entre Santo Domingo y Astillero... En ambos lotes, la Inca Rubber explota caucho goma Mollendo fina, mediante el sistema de tichelas, los exporta por Mollendo cargándolos en mulas hasta Tirapata, tan luego por ferrocarril [...]"

Los acuerdos entre Chester Browmn y el Estado peruano habían significado el logro de grandes ventajas para el estadounidense, tales como:

- La Inca Rubber Co. debía ser compensada con 1000 hectáreas de tierras de montaña por cada kilómetro de vía carrozable entregado al tránsito.

- Inca Mining Co. debía recibir 500 hectáreas por cada kilómetro de camino de herradura.

- Cobrar peaje a los transeúntes.

- Cobrar almacenaje a los comerciantes.

- Cobrar pastaje por las acémilas que transitaban por dichos caminos.

Chester Browmn, además de concesionario de caminos era propietario de las dos empresas. Al final, por los 382 kilómetros construidos o reabiertos, Ch. Browmn se hizo de l'090,000 hectáreas de bosques de gomales, cascarilla, maderas. Un informe de aquellos años da los siguientes alcances sobre la vía habilitada por la Inca Rubber Co. y la Inca Mining Co.

Transitar por aquella ruta de $382 \mathrm{~km}$ de longitud, entre la estación ferrocarrilera de Tirapata (Azángaro) y el puerto fluvial de Astillero, suponía:

- Trasladarse a pie o en acémilas durante más de una semana por lugares totalmente desolados y sin servicio alguno.

- Enfrentar las altitudes, pues desde la estación ferrocarrilera de Tirapata a $3883 \mathrm{msnm}$ se tenía que ascender a 4.917 , nivel del Abra de Aricota, para luego descender hasta 245 msnm, en una compleja topografia.

- Soportar temperaturas extremas desde el frío cordillerano hasta el calor de los trópicos. A todo ello se deben sumar las lluvias, vientos, soledad o inseguridad, carencia absoluta de

\begin{tabular}{|c|c|c|c|}
\hline \multirow{2}{*}{$\frac{\text { Jornada }}{\text { 0l día }}$} & \multirow{2}{*}{$\begin{array}{l}\text { Lugares } \\
\text { Tirapata }\end{array}$} & \multicolumn{2}{|c|}{ Km. Alturas msnm } \\
\hline & & 00.00 & 3,881 \\
\hline & Asillo & 25.00 & 3,883 \\
\hline & Finca Casa Blanca & - & - \\
\hline & El Recreo & 49.99 & \\
\hline \multirow[t]{2}{*}{01 día } & Chislluma-San Antón & 50.00 & - \\
\hline & Finca Triunfo & 58.00 & \\
\hline \multirow[t]{3}{*}{01 día } & Finca Carmen & 86.00 & 4,087 \\
\hline & Finca Puerto Arturo & 94.00 & 4,178 \\
\hline & Crucero & 118.00 & 4,385 \\
\hline \multirow[t]{6}{*}{ 0I día } & Abra Aricota & 155.00 & 4,217 \\
\hline & Huancurani & 168.00 & 4,186 \\
\hline & (Almacén Inca Mining) & 173.00 & \\
\hline & Limbani & 180.00 & - \\
\hline & Agualiani & 185.00 & - \\
\hline & Oconeque & - & - \\
\hline \multirow[t]{5}{*}{ 0ldía } & (Finca de Inca Mining) & - & - \\
\hline & Hotel Quinton & 210.00 & - \\
\hline & Sagrario & & \\
\hline & (Almacén Inca Mining) & 230.00 & . \\
\hline & Oroya & - & \\
\hline $1 / 2$ dia & Finca de Inca Mining & 240.00 & \\
\hline \multirow[t]{3}{*}{ 0ldía } & Mina Santo Domingo & 255.00 & 1,740 \\
\hline & Abra & 286.00 & \\
\hline & Campamento Nro. 5 & 290.00 & 1,777 \\
\hline \multirow[t]{3}{*}{ Oldía } & Finca de Inca Rubber & 317.00 & - \\
\hline & Huacamayo & 367.00 & \\
\hline & Candamo & - & \\
\hline \multirow[t]{3}{*}{ 0ldía } & Almacén Inca Rubber & 252.00 & 266 \\
\hline & Astillero & $282.00 \mathrm{~km}$ & \\
\hline & (Puerto Río Tambopata & & \\
\hline \multicolumn{2}{|c|}{ Total: 08.5 dias } & $382.00 \mathrm{~km}$ & \\
\hline
\end{tabular}

asistencia en caso de accidentes; asimismo, los riesgos durante la navegación, sobre todo en la Selva Alta.

También aquellos $382 \mathrm{~km}$ de caminos de herradura estaban totalmente controlados

Vía Tirapata - Tambopata.

\begin{tabular}{|c|c|c|}
\hline Tramo & Distancia en kms. & s. Concesionaria \\
\hline 1. Tirapata-Limbani & 180 & Inca Minig Co. \\
\hline 2. Limbani-Sto. Domingo & 75 & Inca Mining Co. \\
\hline $\begin{array}{l}\text { 3. Sto. Domingo-Astillero } \\
\text { (Tambopata) }\end{array}$ & 27 & Inca Rubber Co. \\
\hline Total & $382 \mathrm{~km}$. & $\therefore$ \\
\hline
\end{tabular}




\begin{tabular}{lll}
$\begin{array}{lll}\text { Peajes. } \\
\text { Concesionaria }\end{array}$ & Concepto & Tarifa \\
\hline Inca Minig Co. & $\begin{array}{l}\text { Trocha carrozable, } \\
\text { por mula } \\
\text { Camino de herradura }\end{array}$ & $\begin{array}{l}01 \text { sol y } 80 \\
\text { centavos } \\
01 \text { sol }\end{array}$ \\
Inca Rubber Co. & $\begin{array}{l}\text { Trocha carrozable, } \\
\text { por mula }\end{array}$ & $\begin{array}{l}01 \text { sol y } \\
80 \text { centavos }\end{array}$ \\
\hline Total & 05 soles y 30 centavos \\
\hline Fuenk: Trzón Burna, 1911. & \\
\hline
\end{tabular}

por las empresas de $\mathrm{Ch}$. Browmn por lo que tenía asegurada, con creces, la recuperación de sus inversiones en la construcción de dicha via, seccionada en tres grandes tramos.

En realidad aquellas vías no eran públicas, pues el Estado había renunciado a sus responsabilidades, optando por la concesión absoluta sin restricción alguna en favor de las empresas Inca Mining Co. e Inca Rubber Co. incluidos el cobro de peajes, particularmente cuando ingresaban con acémilas trasladando mercancías, y cuando retornaban con carga de caucho-shiringa que por lo demás, eran las únicas vías para trasladarse hacia Madre de Dios. Aquellos peajes tenían los siguientes costos:
En ausencia de algún mecanismo de control por parte del Estado, los costos del peaje estaban sujetos a las decisiones de las empresas de Browmn que, a la vez, no ofrecían las seguridades del caso por cuanto las vías estaban abandonadas, generando las quejas de los arrieros cuyos patrones residían en Arequipa y Lima, aunque finalmente lograron ser oídos por el Gobierno, quien mediante Resolución del 28 de abril de 1904, dio un plazo de seis meses a la Inca Rubber Co. e Inca Mining para que reparasen dichos caminos.

Pero a pesar de las disposiciones gubernamentales, las citadas empresas, que tenían una sola administración, habían expresado su propósito de no atender las órdenes, aludiendo que los costos invertidos no reportaban ningún beneficio. ¿Qué más beneficio podían exigir aparte de las $1.090,000$ hectáreas de terrenos recibidos?

Aquella situación era simplemente insostenible para los comerciantes; así, uno de los más representativos en la actividad, la Sociedad Carpio Márquez, envió la siguiente comunicación:

Lima, 7 de diciembre de 1909.

Exmo. Sr, Ministro de Fomento.

Federico Costa Laurent, por la Sociedad Mercantil Carpio Márquez y Cía., según el poder presentado oportunamente a V.E, digo:

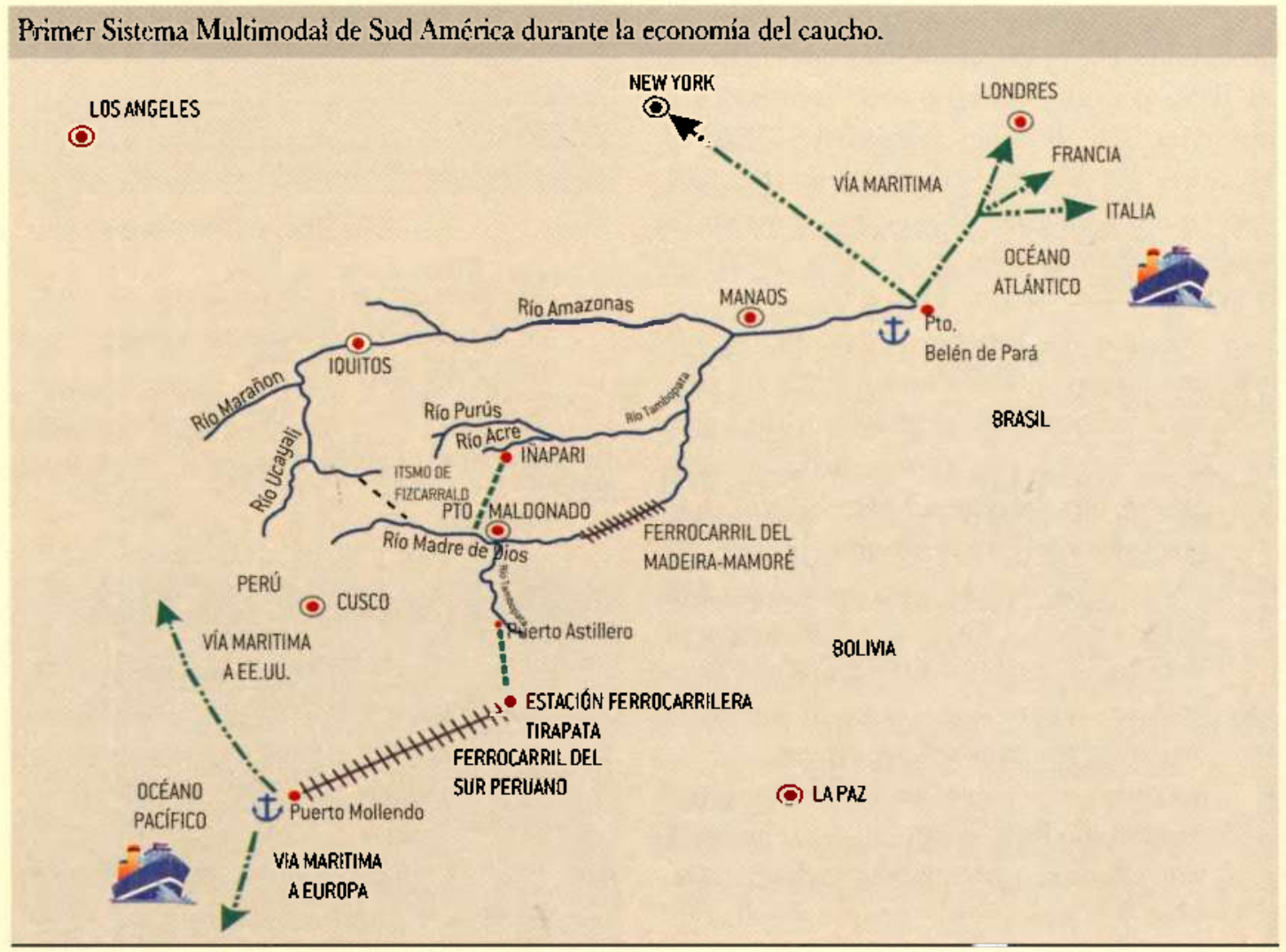


Que acabo de recibir aviso de mis representados, por el que me informan que el Gerente de la Inca Mining y la Inca Rubber Co. se niega rotundamente a dar cumplimiento a la Resolución de V.E. que limita el cobro de los peajes y almacenaje en los caminos entre Tirapata y Limbani, y entre Santo Domingo y Astillero.

Para hacer más eficaz esa desobediencia han ordenado destruir el puerto erigudo en el hugar denominado Candamo con el objeto de interrumpir el tráfico de 600 acémilas pues mis poderdantes, de acuerdo con la Casa Braillard \& Co., deben enviar este mes una inmensa cantidad de mercaderías a Puerto Maldonado para traer a su regreso la cosecha de gomas del año desde la Sucursal de la Casa Braillard en Riberalta - Bolivia. Firmado,- F. Costa Laurent".

(Archivo General de la Nación. Tzerras de Montaña. El subravado es nuestro).

Independientemente de aquellos problemas, ya en la primera década del s. XX, por la importancia de la explotación cauchera, cada vez se fue consolidando un nuevo eje comercial de carácter internacional, el que a la vez era un sistema interoceánico que comprendía el sur peruano, el noroeste boliviano y el centro-este brasileño, siendo los puntos extremos Belén do Para, en la desembocadura del río Amazonas y el Atlántico por una parte, y por otra, el Puerto de Matarani en el Océano Pacífico. Los centros intermedios de aquel gran eje en territorio peruano fueron las localidades de Iñapari, Puerto Maldonado y Tirapata; en Brasil: Xapuri, Empresa -hoy Rio Branco- y Manaos; y en Bolivia, Cobija y Riberalta sobre el río Beni; esta localidad fue fundada en 1892 por los funcionarios de la Compañía Casa Braillard que actuaba en toda la región como compradora de caucho-shiringa y abastecedora de los productos importados. Así, los litorales costeños, los Andes y la Amazonía estaban de algún modo integrados en función del primer sistema multimodal del continente con tramos terrestres, fluviales, ferrocarriles y, finalmente, puertos marítimos.

\section{Primer Sistema Multimodal de Sud América durante la economía del caucho}

Desde luego, el sistema naciente era bastante complejo; sobre todo por los riesgos de la navegación del río Beni, debido a las cachoiras, cachuelas o caidas que generaban accidentes con la pérdida de vidas humanas y mercaderías. Frente a estas serias dificultades la alternativa fue la construcción de ferrocarriles, depósitos, posadas, etc., edificadas por la Casa boliviana Suárez Hermanos en el lugar denominado Cachuela Esperanza, obstáculo natural en la navegación del río Beni, que es un rápido de seis metros de caída por trescientos de extensión; en ese lugar, el lecho del río está cruzado por una rompiente de piedras, según lo denominan los lugareños; en realidad son las últimas estribaciones de la Sierra de Paca Nova.

La Casa Suárez fue capaz de enfrentar tales dificultades; por lo demás, se trataba de una gran empresa:

"Tenía más de mil ochocientos empleados que trabajaban en grandes talleres, barracas y oficinas dotadas de energía eléctrica y permanente comunicación telegráfica. No era raro ver contadores ingleses trabajando en la sede central de la empresa y se construyó un pequeño ferrocarril para evitar las cachuelas que atravesaban el río Madera".

\section{(N. Suárez, 1928)}

Aun hoy existen restos -todo un patrimonio cultural- de aquella ciudadela perdida entre los bosques y que constituye posiblemente el único testimonio de la época de oro de la economía amazónica-boliviana. (N. Suárez, 1928)

Retomando el asunto de la hegemonía de la Inca Mining Co. e Inca Rubber Co. podemos decir

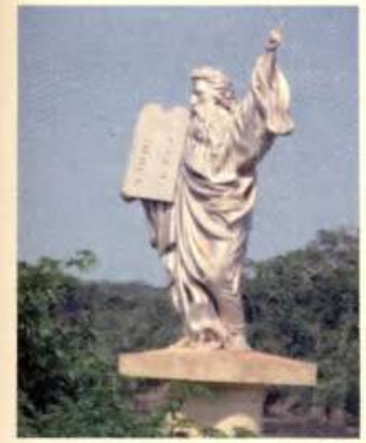

Cachuela Esperanza: Río Beni.
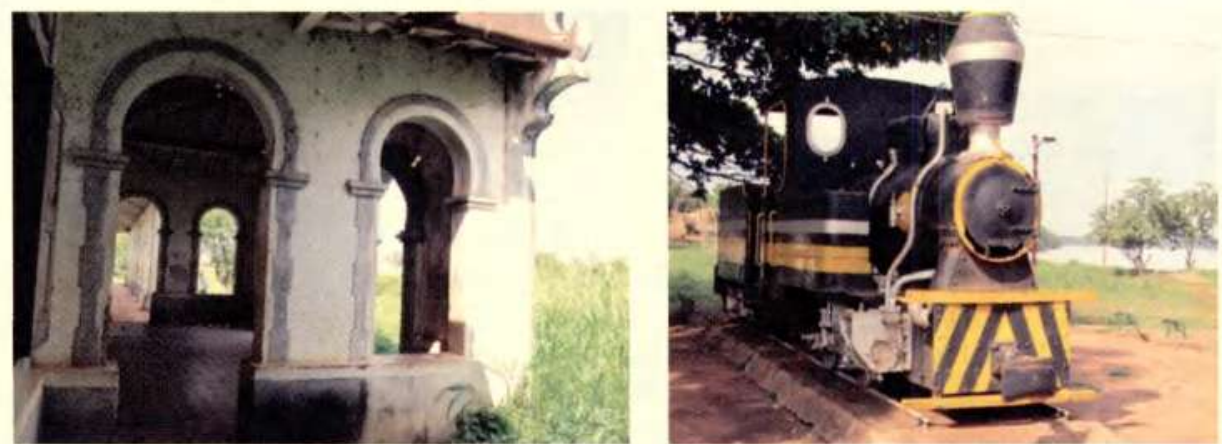
que estas empresas, al abandonar los caminos, incrementaban sus ingresos debido a las siguientes fuentes de ganancias:

- Los depósitos estaban repletos con grandes cantidades de caucho-shiringa de modo que por concepto de almacenaje cobraban sin contemplación alguna.

- Las posadas o alojamientos eran ocupados por tiempos prolongados, pues pocos se aventuraban a trasladar caucho-shiringa con las vías en abandono.

- Las acémilas -mayormente mulas traídas desde Salta, Argentina- requerían de pastos que se encontraban también dentro de los dominios de las empresas de Chester Browmn, constituyendo otra fuente de ingresos.

Así, la situación para los arrieros era insostenible en el tramo comprendido entre Puerto Astillero -sobre el río Tambopata-y Limbani. Las quejas y reclamos eran permanentes:

Memorial presentado por los Arrieros encargados del transporte de caucho a través de la ruta Astillero - Limbani, en contra de la Inca Rubber.

"Arequipa, setiembre 28 de 1909.

Los abajo firmantes hacemos constar de manera verdadera y categórica lo siguiente:

- Que en todo el curso del camino de la Inca Rubber Co. existe pasto natural de producción espontánea que conocemos con el nombre de carrizillo y que siempre ha bastado y ha sido suficiente para el consumo de nuestras mulas que frecuentemente han marchado a Astillero.

- Que las referidas Compañias (Inca Mining e Inca Rubber) tienen pasto solamente en los siguientes campamentos: Pampa Candamo y Astillero en pequeñas extensiones y que se encuentran cuidadosamente cercado con alambres.

- Que no permite la Inca Rubber de modo alguno que las mulas consuman esta clase de pastos cultivados, los que sin la existencia de los naturales no serían suficiente al otro lado para la mantención de las acémilas que trafican por el camino.

Firmado.- Celestino Ocampo, Bernardino Pinto, Mariano Carlín Farre, Bernabé Barreda, Antonio Gómez, J. M Torres, César Rivas, H. Cornejo, Florentino Castro, Nicanor Guillén, Luís Guillén, Clemente Oroz, Saturnino Marcos, Manuel Salas, Filiberto Guillén, José Rondón, Pantaleón Guillén, Santiago Alarcón y otras firmas ilegibles.
El que suscribe Certifica:

Que las firmas que anteceden son auténticas. Arequipa, noviembre seis de mil novecientos nueve.- Firmado, Sebastián Calderón, Abogado y Escribano Público".

$(A G \mathcal{N}-O P P)$.

Muy a pesar de las dificultades señaladas los arrieros y caucheros lograban grandes utilidades en las explotaciones de las gomas elásticas, motivando la presencia de capitales internacionales de diversos origenes. Fue el caso de la empresa Braillard que se había instalado principalmente en territorio boliviano, pero que requería trasladar su carga por el Perú, pues también venía operando en Arequipa y Cusco. De esta manera, para ellos fue vital acceder a los caminos de la Inca Mining y Rubber, para así llegar a la estación ferrocarrilera de Tirapata y continuar hasta Mollendo o Matarani.

También la Braillard manifestaba su descontento ante las arbitrariedades de las empresas de Chester Borwmn por cuanto, el volumen de sus exportaciones de caucho sobrepasaba de 800,000 $\mathrm{kg}$ por exportar. Veamos el siguiente cablegrama.

Braillard Fils, A. \& Co. de París.

Con sucursales en Arequipa, Guzco, Nueva Berna,

Riveralta, Rurrenabaque y Villa Bella.

"Camino Astillero-Limbani en ruta a Mollendo no apta porque Inca Mining Go. viene cobrando derechos antojadizos de pastaje y almacenaje sumamente excesivos y no tarifa aprobada por el gobierno".- 23, setiembre 1909.

(AGN-OPP)

La protestas fueron tomadas en cuenta, sobre todo cuando la empresa Braillard hizo conocer su posición, así el gobierno se vio obligado a regular en algo los derechos de la Inca Rubber y de la Inca Mining:

Resolución Suprema /Lima 19 de noviembre de 1909.

"Visto este expediente seguido por la Sociedad Mercantil Carpio Márquez Co. de Arequipa con motivo del cobro que efectúan las Cías. Inca Mining e Inca Rubber, constructoras y conservadoras de los caminos entregados al servicio público, entre Santo Domingo y Astillero, y entre Tirapata y Limbani en el departamento de Puno y en las Montañas del Tambopata, y por los pastos que consumen las acémilas que lo transitan, así como por los derechos de almacenaje de las mercaderías que por ellos son transportadas. 
$1^{\circ}$.- Que según recibo F- 27, suscrito por el Subgerente de las Cías. mencionadas, D. Víctor Manuel del Carpio, pagó el 6 de julio último cuatrocientos setenta y dos soles, cincuenta centavos por almacenaje de 415 bultos de mercaderías durante los quince días transcurridos, desde el 25 de junio hasta el 10 de julio, a razón de diez centavos diarios por cada bulto.

$2^{\circ}$.- Que la Inca Mining Co. según telegrama de F.46, detuvo en Astillero el 8 de junio último por falta de pago de cuatro días de almacenaje, la carga íntegra de Carpio Márquez Co. obligando a estos a despachar varias canoas llegadas de Puerto Maldonado para transportarla, no obstante haberle propuesto los mismos Carpio Márquez y Co. consignar seiscientos soles en un banco o abonar doscientos al contado, mientras el gobierno expidiera una tarifa.

$3^{\circ}$.- Que don Hermenegildo Araníbar pagó el 13 de setiembre último según recibo F. 64, suscrito por el cajero de la Inca Rubber Co. la suma de doscientos cuarenta soles, por los pagos de consumo de pastos por 16 acémilas, durante cinco días, en el trayecto del camino de Santo Domingo a Astillero.

$4^{\circ}$.- Que teniendo Carpio Márquez Co. en mayo último, que enviar a Astillero 60 mulas cargadas para cumplir su compromiso pactado al amparo de la Resolución de 30 de octubre de 1908, que libre de tráfico de los caminos citados, fueron notificados, por Inca Mining Co. de que no sería permitido el tráfico si no abonaban previamente la suma de un mil doscientos soles a que equivalía el pastaje de 60 acémilas a tres soles cada una en los diez días que comprende el viaje de ida y vuelta.

$5^{\circ}$.- Que la Inca Mining Co., y la Inca Rubber Co. exigen el pago de estas gabelas independientemente del derecho de peaje que están autorizados para cobrar conforme a la respectiva tarifa, aprobada por el gobierno.

Que The Inambari Para Rubber Status Limites, constructora del camino entre Ollachea y el río Inambari solicitó y obtuvo del gobierno el 3 de setiembre último, autorización para cobrar el consumo de pastos que hagan las acémilas que trafican por dicho camino, en una proporción 14 veces menos que la establecida por la Inca Rubber Co. No obstante las analogías que existe entre los fines que persiguen ambas Cías. y los medios que utilizan

\section{Se Resuelve:}

$1^{\circ}$.- Concédase a la Inca Rubber y Cia., e Inca Mining Co. el derecho a cobrar pastaje en los terrenos colindantes con los caminos que han construido, a razón de veinte centavos por animal y por dia de 24 horas y sólo en el caso de que pasten los animales en los terrenos de las Cias.

$5^{\circ}$.- Las Cias. citadas estarán obligadas a entregar al servicio público el Astillero para cobrar derechos de almacenaje por depósitos de capacidad suficiente para guardar las mercancías que se importe a la hoya del Madre de Dios y las que se exporten por la vía Mollendo.

$6^{\circ}$.- Cuando la permanencia de las mercaderías en los depósitos de Astillero exceda en diez días tendrán las compañías derecho para cobrar almacenaje a razón de 10 centavos diarios por metro cuadrado.- Regístrese y comuniquese.Firmado, Larraburre y Correa." (AGN-OPP).

Tal fue el abandono de los caminos que la Sociedad Carpio Márquez \& Co. insistía en sus quejas y protestas contra la Inca Rubber e Inca Mining, haciendo público un documento fechado el 12 de abril de 1911, donde algunos párrafos señalan:

- "Que desde el mes de setiembre de 1910 en que la expresada Compañia despidio a los operarios japoneses, (responsables del mantenimiento de las vías), no han sido reemplazados, el indicado camino se encuentra en el más deplorable abandono;

- Que el estado del camino es tan deplorable que está sembrado de pantanos y las mulas se sumergen en el fango no pudiendo salir de él, teniendo que llevar la carga los arrieros, cuando no se asfixian o son enterrados en el lodo, o en todo caso hay que abandonar la carga;

- Que la Inca Rubber ha cercado todos los pastos naturales del camino y prohibe el acceso a ellos, de manera que nuestras acémilas no tienen qué comer.- Firmas".

(AGN-Archivo General de la Nación. Tierras de Montaña. El subrayado es nuestro).

Sobre los operarios japoneses merece señalarse que el Presidente Augusto B. Leguía había celebrado contratos con la Casa Lockett para conseguir mano de obra japonesa para los plantíos de las haciendas costeñas, donde lastimosamente chocaron con los capataces y administradores que eran casi todos negros expertos en el manejo laboral de los chinos. A causa de los abusos, pronto estalló un motín, muchos retornaron al Japón, otros se asentaron en Lima, algunos empezaron a trabajar en cultivos de panllevar y un centenar marchó hacia la selva sur, hacia Madre de Dios. Al respecto, la prensa del Cusco informaba:

"Han pasado a prestar sus servicios personales a la Inca Rubber y a la Inca Mining Co. alrededor de cien (100) diversos hijos del Imperio del Sol Naciente. 
Hace algunos meses en aquella Empresa se ven en la imposibilidad de ensanchar sus negocios y regularizar su servicio de canoas en la región del Tambopata, por falta de brazos.

En aquella región de chunchos, los indios de la sierra a los pocos días de viaje, se enferman, se aburren o se mueren, aunque la Empresa contrata mestizos y poco más o menos, corren la misma suerte que los anteriores.

La Inca, por estos tiempos solicita una partida de extranjeros intrépidos y robustos.

Agotados todos los medios, tienta hoy la Inca, expandir sus negociaciones valiéndose de la indomable energía japonesa.
El Kasaru Mamaru ha traído a Mollendo de paso para el campamento Santo Domingo (sede de la Inca Mining Co.), cien pequeños nipones, tras ellos vendrán 200 y después 1000 .

Dentro de pocos años, tendremos en nuestra región oriental un almácigo de amarillos de ojos oblicuos, que bajo la sombra del trabajo fecundo, entonarán el Bonzai de sus inmutables triunfos y entonces... Indios, mestizos y blancos, hombres de poca $f e$, seres de energías enfermas, dementes enervados por el vicio, contemplarán desde su miserable covacha, la apoteosis de la perseverancia y el esfuerzo.

Verán, agonizantes, desde su propio lecho, el triunfo de la vida y la marcha, hacia extranjeras playas, de las fabulosas riquezas que encierran nuestros vírgenes bosques [...]" (Cusco, El Comexcio del 4 de abril de 1907).

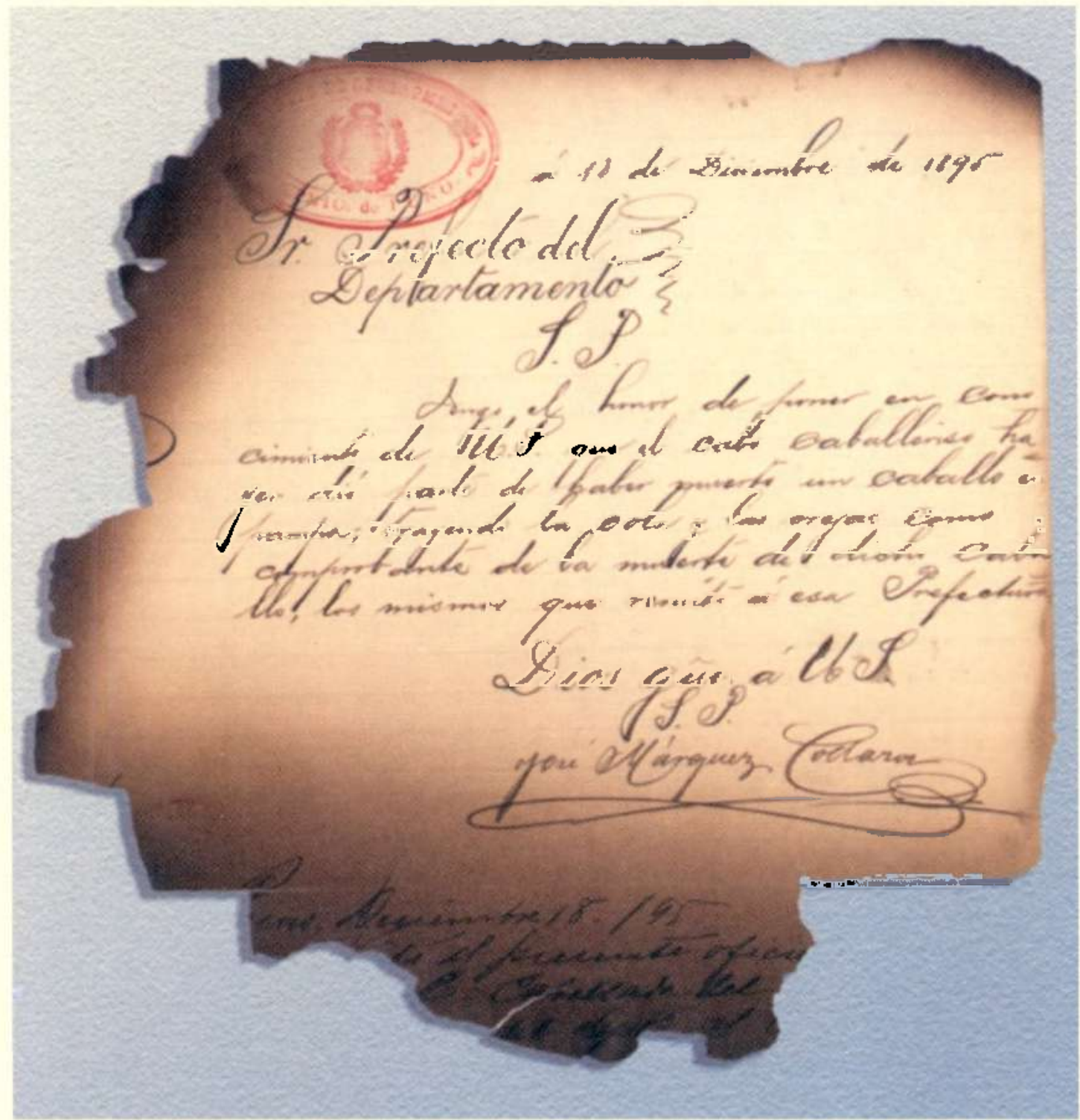

Carta al Prefecto de Puno informado sobre la muerte de una acimila. 10 de diciembre de 1985. Frapmento obtenido en el Archivo Regional de Ptrno.). 


\begin{tabular}{lr} 
Mes & Monto en soles \\
\hline Agosto & $2,537.84$ \\
Setiembre & $8,798.46$ \\
Octubre & $12,213.79$ \\
Noviembre & $14,319.80$ \\
\hline Total: & $37,869.89$ \\
\hline Fucent: Artian General de la Vación. Elaboracioin nuestoc, 2009.
\end{tabular}

Así la Rubber Co, y la Inca Mining contaban mano de obra japonesa, parte de ella destinada al mantenimiento de las vías; otras, a la agricultura e inclusive al transporte fluvial. Fernández Moro (1952) informaba:

Carta al Prefecto de Puno informado sobre la muertede una acémila: IO de diciembre de 1985. Fragmento obtenido en el'Arkioo Regional de Puno.

"En Astillero permanecí cinco días esperando canoa, y el 6 de agosto de [19]0] nos embarcamos en un batelón de la Inca [Rubber], inipulado por doce japoneses: nada ocurrió el día 6 [...]

El día 7, domingo, tenía que ser de peripecias, y una prueba para los superticiosos, que dicen no creer en Dios y creen en mil majaderias.

Serían las 10:20 de la mañana, cuando al atravesar una fuerte correntada y chocando la popa con un tronco, se le abrió un hueco de 30 centímetros, lo suficiente para que el batelón se viese lleno de agua [...]"

En realidad las víctimas del abandono de las vías eran los arrieros, quienes enfrentaban las dificultades en los diversos caminos de herradura, por lo que una y otra vez insistían en sus pedidos, también enviaron un Memorial de reclamo al Gobierno:
"Los suscritos, arrieros de la recua de Norberto Terrazas, contratada por los señores CarpioMárquez Co. hacemos constar que los caminos cuya conservación están a cargo de la Inca Rubber Co., desde Tirapata hasta Astillero se encuentran en peores condiciones...

Que con la recua del referido Terrazas ha sucedido algo grave, que de 25 mulas cargadas que entraron para sacar carga de caucho, solamente han salido 16 mulas (...)" Tijrapata, abril 19 de 191 l.- Fdo. Norberto Terrazas, Santiago Terrazas y otros". (AGN-OPP / Subrayado nuestro).

Para aquellas economías, tanto era el valor de las acémilas que el mismo gobierno tomaba los recaudos para el cuidado de las acémilas asignadas a la gendarmería o policía en el Altiplano; y en caso de muerte del animal estaban obligados a presentar un informe detallado, acompañando una prueba: la cola, orejas o el cuero del animal.

Si los caminos estaban en abandono, las utilidades de las empresas de Chester Browmn cada vez crecían más, por lo que la Cía. CarpioMárquez, daba a conocer el monto pagado a la Inca Rubber Co. por dicho concepto en 1910:

El Gobierno, ante las quejas constantes y debido al abuso de las empresas Inca Mining Co. e Inca Rubber, finalmente no tuvo otra alternativa que rescindir la concesión.

Resolución del 10 de agosto de $19 / 1$

"[...] Se Resuelve:

Asúmase por el Estado a partir de esta fecha la posesión de los expresados caminos entre Tirapata y Puerto Astillero, con sus anexos respectivos.Regístrese, Comuníquese y Publiquese.- Firmado, Ego Aguirre". (AGN-OPP).
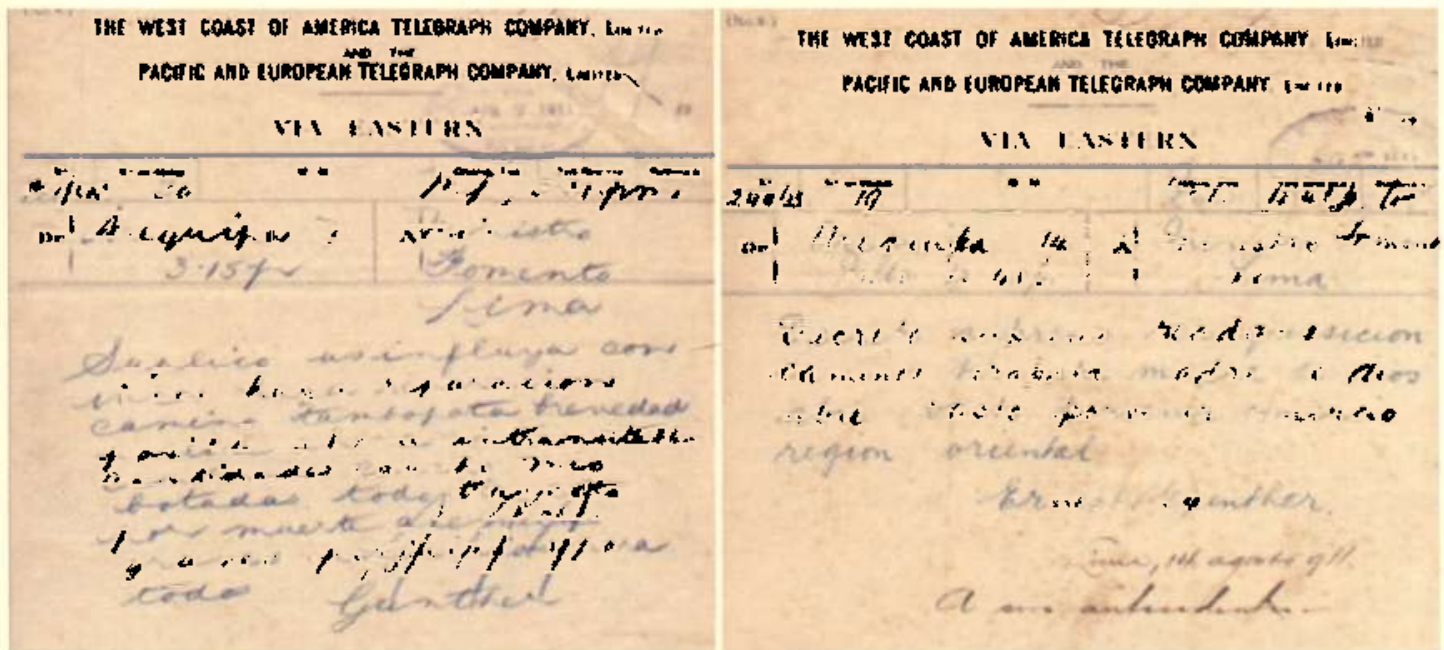

Telegramas enviados por el St. Enesto Gunther diviqidas al Ministro de Fomento, 1911. 
La Inca Mining y la Inca Rubber, no aceptaron la decisión gubernamental, impugnando dicha resolución; sin embargo, el Gobierno para bien de los usuarios, se ratificó en su decisión, aunque la Inca Rubber seguía operando en la región.

"Resolución Suprema, 03 de diciembre de 1909.

Vista la solicitud de José de la Rosa, apoderado de las compañías Inca Rubber e Inca Mining, constructoras y conservadoras de los caminos entre Santo Domingo y Astillero y, entre Tirapata y Limbani, en el departamento de Puno y hacia Madre de Dios, por la que pide se reconsidere la Resolución del 19 de noviembre último, que prohibe a dichas Compañias cobrar derechos de pastaje y almacenaje en la proporción que tenían establecidas y limita las sumas de dinero que deben percibir por estos servicios.

Resuelve:

No ha lugar la reconsideración de la Resolución de 19 de noviembre último que solicita don José de la Rosa.- Firmado, Larraburre"

(AGN-OPP. El subrayado es nuestro).

Esta decisión fue saludada por muchos comerciantes y patrones de arrieros como el $\mathrm{Sr}$. Ernesto Gunther y otros. Gunther, con sólo poseer algunas recuas de acémilas, logró acumular una gran riqueza. Aquel alemán transportista de gomas elásticas a través del sistema de arrieraje, fue uno de los afortunados por cuanto las altas utilidades obtenidas le permitieron diversificar sus actividades empresariales, llegando a instalar una fábrica cervecera en el Cusco. Leamos a continuación las comunicaciones de Sr. Gunther.

Muy a pesar de las decisiones gubernamentales no hubo mayormente cambios en el accionar de Inca y Mining Co. los transportistas persistieron en sus demandas y así se fue generando una tensión. El Estado frente a dicha situación tomó medidas drásticas llegando en algunos casos a la expropiación de bienes.

"Resolución Suprema, Lima 11 de agosto de 1911

"[...] Que la primera de las Compañías (Inca Mining) es propietaria de 10,549 hectáreas de tierras que se extienden en una faja de 50 metros de ancho a todo lo largo y a ambos lados del camino, desde el campamento $\mathrm{N}^{\circ} 04$ hasta Astillero, comprendiendo una extensión longitudinal de $105 \mathrm{~km}$.

Se Resuelve:

El Ministerio de Fomento expropiará en la extensión y lugar que sean convenientes para el establecimiento de estaciones, almacenes, depósitos, bodegas, tambos y ensanches de via [...]".- Fdo.Ego Aguirre. (AGN-OPP. Subrayado muestro).

Verdadero conflicto entre el Capital y el Estado débil, incapaz de asumir sus responsabilidades, sobre todo en aquellos tiempos de definiciones que pudieron haber sentado las bases del Estado-Nación, pero que sucumbieron por obra de las aristocracias que se habían hecho del poder. Ya más adelante, conociendo en detalle el problema de las vías, trató de modificar las condiciones de administración de los caminos en los siguientes términos:

Resoluctón Ministerial /Lima 19 de julio de 1912

Considerando:

Que el camino carretero de Tirapata a Huancarani y los de herradura de Huancarani a Santo Domingo y de este lugar a Astillero, únicos en la actualidad que dan acceso a la hoya del Madre de Dios, han sido entregados en administración a la compañía Inca Rubber y a la Sociedad Carpio Márquez Co., por resoluciones de 22 de setiembre último.

\section{Se Resuelve:}

La Administración de los caminos de Tirapata a Astillero, así como el Inspector Técnico e Interventor Fiscal en ellos dependerán, en lo futuro, directa e inmediatamente, de la Dirección de Obras Públicas, a cuyo poder pasará la de Fomento todos los antecedentes relacionados con esas vías.- Regístrese y comuníquese".- Firma ilegible. (AGN-OPP. El subrayado es nuestro).

La Inca Rubber Co. no se quedó tan sólo en explotar caucho, construir y administrar caminos, también, incursionó en el servicio fluvial; por lo demás, era propietario de almacenes en Puerto Astillero, sobre el río Tambopata. De esta manera, habiendo logrado armar en dicho lugar el vapor Inca, empezó a ofrecer dicho servicio y las precarias balsas y frágiles canoas paulatinamente fueron dejadas de lado. En tales condiciones, nuevamente los conflictos de intereses se agudizaban y fueron los comerciantes, en su mayoría procedentes de Arequipa, quienes pugnaban por ser atendidos en sus reclamos por cuanto los privilegios de la Inca Rubber Co. eran evidentes. La Sociedad Mercantil Carpio Márquez Co. encabezó gran parte de los reclamos.

Los competidores de la Inca Rubber no se quedaron conformes con que el Estado asumiera el mantenimiento de los caminos, por lo que la Sociedad Carpio, finalmente, logró asumir el control y mantenimiento de la vía. 
Sistema Internacional de Transporte de Gomas

Ruta: Puerto Maldonado-Europa, vía ferrocarril Madeira-Mamoré.

\begin{tabular}{lrrr} 
Origen del & Destino & Med. de transp. & Tiempo de viaje \\
\hline Centros caucheros & Pto.Maldonado & Balsa o canoas & 08 días \\
Pto. Maldonado & Cachucla Esperanza & Lancha o vapor & 05 días \\
C. Esperanza & Camino de herradura & Camino & 02 días \\
C. Esperanza & Villa Bella & Camino & 01 días \\
Villa Bella & San Antonio & Lancha a vapor & 02 días \\
San Antonio & R. Amazonas Pto. Belén & Ferrocarril & 05 días \\
Belén do Para & Europa & Barco & 45 días \\
Belén do Para & Estados Unidos & Barco & 35 días \\
Total promedio & Centros caucheros hasta el Pto. Liverpool & Barco & 68 días \\
& Centros caucheros hasta el Pto. N. York. & Barco & 58 días \\
\hline Fuente: Archivo Ceneral de la Nación. Elaboración nuestra. 2009. & &
\end{tabular}

"Resolución Suprema, Lima 22 de setiembre de 1911

Visto el recurso por el que la Sociedad Carpio Márquez y Co. de Arequipa se ofrece encargarse del camino de Santo Domingo- Puerto Astillero, que da acceso a la montaña de Madre de Dios sin alterar tarifas de viaje vigentes, construyendo tambos en los lugares apropiados para el mejor servicio, proporcionando viveres a la guarnición de Madre de Dios y rebajando al gobierno diez por ciento sobre los precios que por su carga y pasajeros ha pagado a las Cias. que han administrado.

Se Resuelve:

Entréguese a la Sociedad Carpio la Administración del camino entre Santo Domingo y Astillero por cuatro años, vencido los cuales se puede renovar..."

$(A G N-O P P)$.

\begin{tabular}{lrrr}
$\begin{array}{l}\text { Sistemade Transporte en el cje Callao - Puerto Maldonado } \\
\text { Origen del } \\
\text { transporte }\end{array}$ & DestinoDías de jornada & $\begin{array}{r}\text { Medio de } \\
\text { transporte }\end{array}$ \\
\hline Callao & Mollendo & 03 & Vapor \\
Mollendo & Arequipa & 01 Ferrocarril \\
Arequipa & Juliaca & 01 Ferrocarril \\
Juliaca & Tirapata & $\square$ Ferrocarril \\
Tirapa & San Antón & 01 & Mula \\
San Antón & Crucero & 01 & Mula \\
Crucero & Limbani & 01 & Mula \\
Limbani & Sto. Domingo & 03 horas & Mula \\
Sto.Domingo & Guacamayo & 02 & Mula \\
R.Guacamayo & Pto. Candamo & 03 horas & Mula \\
Pto. Candamo & Astillero & 03 horas & Mula \\
Astillero & Pto. Maldonado & 03 & Canoa \\
Retorno: & Candamo & 10 a 14 días & Canoa \\
Pto. Maldonado & & & \\
\hline
\end{tabular}

Fuente: Archiro General de la Nación. Elaboración nuestra, 2009.
Muy a pesar de estas decisiones gubernamentales, los conflictos no habían cesado, la Compañía Carpio Márquez Co. finalmente asumió la concesión de los caminos desde Santo Domingo hasta Puerto Astillero, de manera que Inca Rubber e Inca Mining, luego de diez años de administración de dichas vias, tuvieron que retirarse. Asimismo, los nuevos concesionarios trataron de promocionar la vía al servicio de otras empresas; para el efecto, invitaron a Braillard, recibiendo la siguiente respuesta:

"E. Braillard \&- Co."

Arequipa-Cusco

Cable Codes Used - Liebres A. l, A.B.C. 4 th \& 5

th Ed. Código Telegráfico Anglo-Español

Arequipa, 27 de julio de 1911.

Señores Carpio-Márquez \& Co.

Lima.

Muy señores nuestros:

En respuesta a su atenta, de 22 del actual, cumplimos con manifestarles que ya hemos iniciado el tráfico, por la ruta del Tambopata, tanto de importación como de exportación para Bolivia-Riberalta, pero como hasta ahora esta ruta no nos ha presentado ventajas en cuanto a la rapidez, necesitamos tener ventajas, para continuar con ella.

Las cantidades en tránsito serán $\mathrm{m} / \mathrm{m}$ de unos 10000 qq de entrada y otro tanto de salida, pero no estando seguros de estas cifras vamos a escribir a $n$ / amigos de Riberalta para que nos las indiquen fijamente.

La diferencia entre el flete de esta ruta y la del MaderaBrasil es exigua y lo que necesitamos es la ventaja de rapidez que ofrezca cualquiera de estas rutas para efectuar por ella en tránsito de n/ carga. 
Actualmente el transporte de $\mathrm{n} /$ importación y exportación por la vía Tambopata se hace con mucha lentitud y no conviniéndonos esto, como Ud., comprende, le repetimos que hay necesidad de que nos ofrezca más ventajas en cuanto a la rapidez.- Sin otro particular por el momento, aprovechamos de la oportunidad para repetirnos sus siempre attos. y ss.ss.Firmado, Braillard \& Co".

\section{$(A G N-O P P)$.}

Más allá de los problemas señalados, cada vez se iba consolidando el eje regional Madre de Dios-Puno-Arequipa (Mollendo), de donde se proyectaban hacia Lima-Callao, ruta que demandaba ser transitada por el siguiente itinerario:

En promedio los viajes duraban dos semanas, alternado días mediante vapor, ferrocarril, camino de herradura y navegación fluvial. Este medio tan complejo de altos riesgos, costos y tiempo prolongado, siempre fue un reto para los shiringueros, caucheros, comerciantes y para cuanta persona deseaba ingresar hacia Madre de Dios, motivo por el que siempre estuvo presente la idea de buscar alternativas viales para el transporte; así surgía la posibilidad aguas abajo del río Madre de Dios, accediendo hacia el Mamoré-Madeira, luego al Amazonas, para continuar a su destino final: los mercados norteamericanos y europeos.

Desde luego, cada ruta nacional o internacional tenía sus propias especificidades en cuanto a costos, tiempos, facilidades o dificultades. Así, el tiempo de transporte de las gomas de Madre de Dios-Acre hacia los mercados europeos, en promedio era de dos meses, alternando desde el carguío de las bolachas en acémilas hasta la precaria balsa o canoa, ferrocarril y vapor marítimo, como se puede notar en el siguiente detalle:

Dentro del propósito de lograr la integración fisica de aquellas regiones, se impulsó la apertura o reapertura de caminos desde inicios del s. XX, con las alternativas siguientes.

Sistema Internacional de transporte de Gomas Ruta: Puerto Maldonado-Puerto Mollendo-Europa.

Tramos Medio de transporte Tiempo en días

\begin{tabular}{lrr}
\hline Pto. Maldonado-Astillero & Canoa & 9 dias \\
Astillero-Tirapata & Acémilas & 14 días \\
Tirapata-Mollendo & Ferrocarril & 3 días \\
Mollendo-Europa & Barco & 42 dias \\
\hline Total &.- & 68 días \\
\hline Fuente: Archivo General de la Nación. Elaboración nuestra 2009. \\
\hline
\end{tabular}

Primer camino, a cargo de la Compaña Lemaitre, partiendo del Araza, continuaba su rumbo hacia el río Rosario, afluente que desemboca en el río Tambopata, aproximadamente a 25 kilómetros más arriba de Puerto Markham. Se tenía la seguridad de que dicho camino favorecería la corriente comercial en las cabeceras del Tambopata, donde existen grandes pastizales a fin de dar facilidades a los arrieros que trasladaban mercancías para dotar a los caucheros, y de retorno se sacaba gomas.

Segundo camino, como ya señalamos, construido por la Inca Mining Co. desde la estación de Tirapata, en el Ferrocarril del Sur Cusco-Puno. Conforme se incrementaba el comercio cauchero, luego la explotación de oro aluvial, Tirapata fue cobrando gran importancia, llegando a contar con diversas oficinas, casos de la Inca Rubber Co. Inca Mining Co., Carpio Márquez y Co., Gold y Draguing Co., entre otras.

Conforme se mejoraban los caminos que trataban de llegar a la confluencia del río Távara con el Tambopata -punto desde el cual, era posible la navegación a vapor hacia el río Madre de Dios-, había un mayor ingreso de migrantes, todos en función de la explotación cauchera, inclusive empezaron a ingresar hacia el río Sonene -hoy río Heathestas circunstancias facilitaron también una mayor presencia de la administración estatal mediante la instalación de Sub-comisarías sujetas a la Comisaría Principal del Madre de Dios, establecida en Puerto Maldonado.

Otro de los circuitos o itinerarios mercantiles fue Sandia-Chunchusmayo, camino establecido en tiempos anteriores aún al virreinato y que era vigilado y sostenido por las autoridades de la provincia de Sandia. En esta zona operaba The Tambopata Rubber Sindicate Limited, empresa inglesa con domicilio en Londres que, según sus documentos de constitución, tenía como objetivos, además, de la extracción y comercialización de las gomas elásticas, los siguientes:

- Comprar y explotar las haciendas El Porvenir y La Unión, al oeste del río Tambopata.

- Explotar las concesiones de gomales hechos en Bolivia a Carlos Frank.

- Adquirir construcciones y otras propiedades.

- Construir ferrocarriles, abrir caminos, muelles y otras obras que considerasen necesarias. 
- Comprar y fletar barcos, prestar dinero con o sin garantía a personas o corporaciones y adquirir préstamos mediante la emisión de bonos o hipotecas.

Al final The Tambopata Rubber sólo se dedicó a la explotación y comercio del caucho, logrando posesionarse de 96,626 ha, donde se abrieron 1,000 estradas, todo ello en las proximidades de los ríos Heath, Madre de Dios y Tambopata, aunque su centro de operaciones fue San Carlos, a orillas del río Colorado, afluente del Tambopata; además de la barraca más importante que estaba en la localidad denominada Marte. Como todas las empresas de aquel entonces, sus métodos de trabajo se sustentaban en el sistema de la época, enganche por deudas, aunque iban más allá, atropellando todo tipo de derechos de los trabajadores, indígenas y no indígenas, víctimas de castigos físicos, sobre todo a quienes intentaban huir, fugar o escapar, los que siempre eran capturados con auxilio de la policía, pues la manera de salir de aquellos lugares requería necesariamente de algún auxilio para viajar por los ríos y es cuando eran delatados.

Los propios documentos de Tambopata Rubber (Flores Marìn, 1977) comentan sobre aquellos abusos cometidos. Así el Gerente de la empresa, A.C. Lawrence, desde la localidad de San Carlos escribió una carta a Custodio Vargas, fechada el 30 de mayo de 1910, indicando:

"[...] acerca de las tramas que iban formando ya tuve conocimiento ahora un mes, y es por esto mismo sin perder más tiempo hice que se vengan los de Santo Domingo, quienes han recibido su merecudo correspondiente por sus picardías. $\mathrm{Si}$ acaso no les ha dado a cada uno de los de allí como son Nique y Gil a 100 palos a cada uno; al recibo de la presente les haga subir a 200 [...]" [Sic].

(El subrayado es nuestro).

Otro empleado, de nombre Abel Enríquez, envió una Carta con fecha 20 de octubre de 1911 , dirigido al Gerente de la empresa, señalando:

"Si, yo desde el día que estoy a cargo de todo trabajo en ésta, precisamente los apuro en todo trabajo con un par de látigos o un puntapié lo cual no es para que vayan con quejas donde Ud. no menos que ahora pocos días lo he castigado de otro modo al peón Bellido, sin hacer uso del látigo porque quería huir..."

(El subrayado es nuestro).

The Tambopata Rubber, mediante sus agentes y en complicidad con algunas autoridades locales se aseguraba de mano de obra, inclusive a través de ofensivos contratos como el siguiente:
“... [el trabajador] renuncio al fuero de domicilio y cualquier excepción que me favorezca legalmente y someterme a los juzgados de la provincia y afianzo con mi persona y lo mejor de mis bienes..."

De aquellos contratos hechos al gusto de la empresa, a la venta de indígenas a los patrones caucheros no había mayor distancia, era asunto cotidiano y en el negocio estaban comprometidos por lo general las autoridades locales. Veamos el siguiente telegrama del 27 de julio de 1911 , donde un grupo de campesinos hace una denuncia ante la Asociación Pro Indígena que por esos años comenzaba a trabajar:

"Subprefecto Sandia con gobernadores realizan criminal venta indígenas para gomales San Carlos, nos apalean, nos encarcelan y nos reclutan con'gendarmes para obligarnos, ir por fuerza gomales mortíferos por 6 bolivianos, 11 recibe autoridad; y 15 y 20 , por quepir -cargador- 12 ellos. Estamos prófugos, abandonando familias, intereses [...]"

\section{(El subrayado es nuestro).}

La vil explotación cauchera no sólo llegaba a los pueblos étnicos de la Amazonía, sino también a las poblaciones andinas del altiplano peruanoboliviano, quienes recibían un "adelanto" en moneda boliviana, dinero de valor muy reducido.

Asimismo, la ruta Chunchusmayo-Tambopata, considerada vía de paso a la montaña virgen servía para los propósitos de la explotación caucheroshiringuera y su mejora fue encomendada a la casa M. Forga e Hijos de Arequipa. Esta ruta, de acuerdo a informes de la época, tenía más de treinta cuestas para ascender y con pendientes de $50 \%$ :

"[...] a tal extremo que los quepires tenían que formar una cadena continuada para ir sosteniéndose los unos a los otros y librarse de un desbarranque seguro. Si este trazo va a servir más tarde para construir un camino, resultaría la labor infecunda o contraproducente, puesto que en lugar de abreviar la distancia se hace más inmenso de camino y tiempo, transmontando la infinidad de cadenas y cumbres por las cuales la compañía Forga ha trazado el eje del camino; y que al desarrollar con pendiente uniforme en esa extensión de $123 \mathrm{~km}$. que hoy mide, resultaría casi infinito" (Puerto Markham, mayo 9 de 1902. Juan S. Villalla).

Sobre la infraestructura señalada y base de los circuitos se daban las exportaciones e importaciones por cada una de las rutas. En 1912 las remesas alcanzaban los siguientes volúmenes: 
Asimismo, entre los principales caucheros de Madre de Dios, sus volúmenes de exportación registrados a 1916, fueron:

$\begin{array}{ll}\text { Máximo Rodríguez: } & 225,000 \mathrm{~kg} . \\ \text { Bernardino Perdiz: } & 150,000 \mathrm{~kg} . \\ \text { Souza \& Vargas: } & 120,000 \mathrm{~kg} . \\ \text { Bruno Paulsen: } & 100,000 \mathrm{~kg} . \\ \text { Braillard y Cia.: } & 100.000 \mathrm{~kg} . \\ \text { Varios caucheros: } & 200,000 \mathrm{~kg} .\end{array}$

Además de caucho-shiringa exportaban pieles de fauna silvestre, actividad que se incrementaba a partir de la autorización gubernamental que había obtenido la Casa Máximo

\section{Señor Director de Gobierno.}

Maldonado, 15 de noviembre de 1919.

Lima. S.D.-

Adjunto al presente la solicitud presentada a este Despacho por don Francisco Docet, apoderado de la firma comercial Máximo Rodríguez, solicitando autorización para importar por la Aduanilla de Iñapari a éste Departamento, las siguientes armas:

Procedencia Norteamericana:

24 carabinas Winchester, calibre 44

30 mil cartuchos cargados de bala

4 mil cartuchos cargados de bala 32/38 para revólver

1500 libras de pólvora en latas.

Procedencia Inglesa:

168 escopetas de pistón de un cañón

74 escopetas de pistón de dos cañones

1500 libras de pólvora para caza en latas

60 cajas de 112 libras c/u perdigones de plomo para caza.

Estas especies serán embarcadas bajo facturas del Sr. W.R. Grace \& Cia, de N.York, y R.Singerhurst \& Cia de Liverpool respectivamente. Firmado.Idiáquez, Prefecto. $(A G N-O P P)$.

A mérito de su solicitud, Máximo Rodríguez logró su propósito, así tenía el monopolio en la venta de armas, bajo el respaldo de la siguiente disposición:

Exportación de Gomas por rutas y Volúmenes (1912). Ruta Volumen en $\mathrm{kg}$.

Tambopata - Puerto Matarani 353,648 Alto Madre de Dios-Cusco-Puerto Matarani 135,000 Manu-Iquitos 183,000

Fuente: Emilin Delbog, 1912. Elaboración nuestra, 2009.

\section{Resolución Ministerial}

"Lima, 10 de febrero de 1920.

Vista la comunicación que antecede...

Se Resuelve:

Conceder dicha licencia con las condiciones y restricciones expresadas en los Supremos Decretos de 22 de abril de 1907 y 31 de agosto de 1909.- Regístrese y Comuníquese.- Firmado, Leguía y Martínez." ( $A G N)$.

En realidad, aunque el asunto de las armas tuvo muchas implicancias aún no estudiadas, creemos que tuvo los siguientes efectos:

a. Incremento de delitos, debido a la pérdida de vidas del sector más vulnerable, los indígenas, por cuanto las correrías cada vez crecían y no había instituciones que administraran justicia.

b. Comercialización incontrolada y contrabando de armas, por tratarse de fronteras totalmente abiertas.

c. Incremento desmedido en los ingresos de aquella casa comercial, pues el monopolio fue su soporte.

d. Disminución de la fauna silvestre e incremento en la comercialización de pieles, con destino a los mercados europeos y norteamericanos, además se trataba de productos exóticos.

e. Por la falta de moneda o metálico -pues el extractivismo se desarrollaba en base al crédito- para la adquisición de armas se optó por el canje directo con pieles de animales silvestres. Así, una (01) escopeta, equivalía a 60 cueros de tigrillo (Leopardos pardalis), venado (Mazama americana), huangana (Tayassu pecari) y sajino (Tayassu tayacu).

Los siguientes tres años a la autorización de importar armas, la remesa de pieles fue la siguiente:

- $\quad 106,610.5 \mathrm{~kg}$. (setiembre-diciembre)

- $\quad 363,648.5 \mathrm{~kg}$. (enero-diciembre)

- $\quad 30,161.5 \mathrm{~kg}$. (encro-abril)

Aquellas cifras representaban un desembolso de 1.300,000 Libras Peruanas como valor de fletes y transportes. De esta manera los circuitos comerciales no sólo tenían como soporte la exportación de gomas elásticas sino otras mercaderías; así, en 1911, por la vía del Alto Madre de Dios, ingresaron 127,000 kg de carga procedente de Arequipa y Cusco, y por el río Manu 1 11,500 kg procedente de Iquitos. 
Desde luego, en la primera década del s. XX la ruta más importante de todas fue la de TambopataCarabaya, por donde se habría transportado alrededor del 50 por ciento de las gomas (cauchoshiringa); le seguía en importancia la ruta de los varaderos del Manu hacia el Ucayali e Iquitos.

Aquellos circuitos mercantiles, volúmenes y tipo de carga, en 1912, sufrieron algunas alteraciones con la puesta en funcionamiento del ferrocarril Madera-Mamoré, construido a partir del arreglo fronterizo entre Brasil y Bolivia, aunque el proyecto nació en 1846, hasta que en 1867, los ingenieros José y Francisco Keller organizaron una gran expedición para una posible ferrovía; y en 1869 George E. Church obtuvo del gobierno boliviano la concesión para crear una empresa que explorase las alternativas de navegación entre los ríos Mamoré y Madeira, luego Church cambió los planes enfocándose en la posibilidad de construir el ferrocarril como también conocido ferrocarril del diablo, obra llevada a cabo entre 1907 y 1912.

Dicho ferrocarril generó todo un debate en el Sur Peruano, particularmente en Lima, por cuanto se puso en cuestión la competencia en relación a los costos de transporte de la ruta Tambopata. Según Emilio Delboy (1936), sería 18 por ciento más alto que la ruta del ferrocarril Madera-Mamoré.

Si bien el destino del ferrocarril MaderaMamoré fue construido con el propósito de transportar el caucho y otros productos, tuvo un mal desenlace debido a la caída vertiginosa del precio del caucho-shiringa en el mercado mundial, al que se sumó la entrada en servicio del Canal de Panamá en 1914; así el ferrocarril fue deshabilitado parcialmente en la década de 1930.

Fueron estos los itinerarios mercantiles de la explotación cauchera en el Sur del Perú durante las primeras décadas del s. XX, situación que se alteró sustancialmente con la crisis de la economía de las gomas elásticas en la Amazonía. Hoy pareciera nuevamente moldearse en concordancia al actual proceso de reterritorializaciòn motivado por la vía Interoceánica Sur, hecho que tendrá serias incidencias en la nueva fisonomía regional de las próximas décadas pero que lastimosamente no es estudiada; tal vez terminemos viendo que delante nuestro funcione una faja transportadora de exportaciones provenientes del Brasil con destino al mercado de este siglo la Cuenca del Pacífico.

En conclusión, los itinerarios comerciales en función al extractivismo mercantil cauchero- shiringuero, durante las primeras décadas del s. $\mathrm{XX}$, fueron:

1. Manu-Alto Madre de Dios. Carga trasladada por río, luego mediante arrieros hasta Angostura-Cusco, accediendo también al ferrocarril del Sur con destino a Matarani o Mollendo. Por esta vía, la extinguida Compañia Comercial de l'Ämerique du Sud, trasladó -en piezas desarmadas de $120 \mathrm{~kg}-$ la lancha Patria, desde Huambutío hasta el Pilcopata-Pongo de Qoñeq.

2. Inambari-Araza. Hacia Marcapata y Santa Rosa -uno, por las faldas de la cordillera de Chimboya, ruta muy dificil que parecía ser poco utilizada; fue la ruta exclusiva de la empresa Inambari Para Rubber Co. que también trasladó en piezas desarmadas una embarcación; años más tarde operaba en esta zona la empresa Inambari Gold Co. Ltda.

3. Inambari-Garabaya. Ruta exclusiva de arrieros donde la localidad de San Gabán tenía bastante importancia ya que desde allí se accedía hacia Macusani mediante un camino de herradura

4. Tambopata-Altiplano. Entre el río Tambopata, sus nacientes y el altiplano siempre existió una relación, debido al manejo integrado de los diversos ambientes o zonas de vida practicado por sus habitantes. Esta racionalidad fue totalmente distinta a la implementada por el extractivismomercantil, hecho que también se dio en la cuenca del río Madre de Dios, ámbito que además comprende porciones del Norte de la Región Puno o Altiplano y Este del Cusco; de modo que para aquellos manejos integrados de ecosistemas andino-amazónicos muchas localidades jugaron roles muy especiales, entre ellos Azángaro, realidad descrita por Stiglich (1902) en los siguientes términos:

"Azángaro población de indios[...] donde, como en todo el departamento, circula la moneda boliviana.

Nada más bochornoso, humillante y antipatriótico en extremo como la circulación de moneda extraña en un territorio peruano.

Es deseo general ahí que se haga el canje tanto para el bien del indio, con quien se abusa pagándole en peso y en moneda tan pobre [...

Está unido a Lima, ya por telégrafo [...] para prolongar esta línea mejor es hacerlo por Quiaca y Poto antes que por Sandia, a fin de tomar los 
gomales del Tambopata Alto y encaminarla a Ixianas y el Madidi [...]" (El subrayado es nuestro).

En aquellos tiempos, la ruta AzángaroSandia demandaba de cuatro jornadas y, según nuestro autor, tenía las siguientes características ecosociales:

Primera jornada. Azángaro-Muñani, zona de tierras áridas y de pastos naturales para la ganadería, "[...] se pasan dos templos bien tenidos y donde son frecuentes los escándalos y mojigaterías, danzas, crímenes, ferias y bacanales".

Segunda jornada. Muñani-Moyopampa o Picotani, “[...] zona de tristeza y soledad [...], de vez en cuando un arriero pasa y lo saluda al viajero con un hipócrita masuntay si es al sexo masculino, o masunmay si es al sexo femenino, y significa en abreviatura quechua "ave María purísima, señor o señora".

Tercera jornada. Picotani-Cuyo Cuyo, "[...] presenta de atractivo el nacimiento precioso del Inambari en El Tambillo que es una escalinata sin fin, y el cambio a otro clima.

En Cuyo-Cuyo, a mi regreso arrazaba el tifus, a tal extremo que se contaban veinte muertes diarias como mínimo en una población de tres mil almas, que incluían a las comunidades cercanas; [...] Es importante mencionar que no había médicos que quisieran venir al lugar y que sólo habían 50 gramos de quinina. Vox populi: ique desgraciados estos infelices!. Muchos venian de la montaña de Tambopata con cuatro o cinco soles que habian ganado en treinta dias, además de andar sólo a pie, llevando a espaldas 50 y más libras de peso, casi sin tener que comer en muchos dias. $Y_{i}$ a qué llegaban?, a morir de Tifus, después de haber encontrado a sus parientes en menor número $[. .$.$] ".$

Cuarta jornada. Cuyo Cuyo-Sandia, "[...] se pasa ya por plantaciones de papas, maíz, etc. además de crianza de ganado...ya esto puede llamarse montaña... No he encontrado una sola escuela, a pesar de que hay partidas destinadas a tal objeto. Puedo asegurar que no hay honradez en la administración [...]".

Stiglich también señalaba:

"Sandia está situada en un aventadero del torrentoso Chichamaco y un cerro adicional que cuando llueve mucho, llevan oro por las calles, la población con algunapaciencia, opta por recoger las laminillas llamadas climillas [...]

Los habitantes, sólo viven de comidas hechas con chuño y maíz molido, cuando comen carne lo hacen en forma de chalona[...] Esto proviene de la carestía de víveres, pues como se trae a lomo de llama desde Pucará.
El sistema actual para el acarreo de víveres (a cargo de los indios) también es perverso y mal remunerado; pues de los pocos soles que se les da, deben comprar sus viveres. Se les pone siempre 50 libras a las espaldas y tienen que llevar todo en una extensión no menor de 100 kilómetros[...]

A todo trance debe hacerse el camino de herradura hasta el Tambopata[... ] ya se encuentra la shiringa de segunda calidad, asi como el palmito para hacer buenas ensaladas, y fuertes maderas como el huacapú y la capirona. También hay caucho aunque esparcido[...] Por estos lugares hace falta una fábrica de cocaína, pues la coca se vende muy barata[...]"

(El subrayado es nuestro).

Aquella carga proveniente del Tambopata era generalmente transportada en la lancha Inca con una capacidad de 50 toneladas, de propiedad de la Inca Rubber Co. y colocada en servicio en 1904, luego de su construcción en los astilleros de Inglaterra. Desde luego, a partir de Astillero o puerto Markham la tarea le correspondía a los arrieros hasta la estación ferrocarrilera Tirapata -regionalismo que significa desde aqui a las montañas, sólo a pata- ubicada en el km 67.00 de ferrocarril Juliaca-Cusco. Aún hoy existen construcciones destruidas donde hace cien años funcionaban centros comerciales, bancos, almacenes, alojamientos, corrales para las acémilas. Por su importancia, en 1908, se presentó en el Congreso de la República, el Proyecto de Ley N ${ }^{\circ}$ 2913/2008$\mathrm{CR}$, a fin de declarar de necesidad y utilidad pública la construcción del "Ferrocarril Tirapata -Puerto Maldonado- Iñapari", con la finalidad de unir el sistema de transporte ferroviario del sur del país con Brasil, proyecto que de haber prosperado, habría cambiado la situación del Sur Peruano.

5. Manu-varadero de Fitzcarrald. Por donde se trasladó en 1896 -con la fuerza de las poblaciones nativas del Medio Urubamba- la embarcación Contamana del armador Carlos Fermín Fitzcarrald; además, otras embarcaciones como Serjali y Adolfito que naufragó en el Urubamba, muriendo Fitzcarrald y su socio boliviano Antonio Vaca Diez. Aquel varadero o istmo de $12 \mathrm{~km}$ de longitud entre las quebradas Cashpajali y Serjali siempre fue transitado por las poblaciones matsiguengas y otros por cuanto eran sus dominios históricos.

De esta manera, durante la primera década del s. XX existió en Madre de Dios toda una flota mercante con 6 embarcaciones a vapor de mediano porte, tres lanchas de alcohol además de bote-motores, 
representando en total un capital de un millón y medio de Libras Peruanas para un desplazamiento aproximado de 320 toneladas/año, volumen de materias primas de alto valor y demanda en el mercado internacional europeo y norteamericano.

La alta significación económica de la explotación cauchero-shiringuera, motivó el debate sobre las posibilidades de interconexiones ferrocarrileras, encargando a la Casa Arthur Koopel de Berlín diversos estudios preliminares y fue cuando identificaron por ejemplo, la línea que debía partir del kilómetro 67 inmediato a Tirapata, en la vía férrea entre Juliaca y el Cusco, para concluir en el punto llamado Chiforongo sobre el río Inambari, con una extensión de 357 kilómetros. De este modo, debían quedar unidos Mollendo y Madre de Dios en una línea con un total de 900 kilómetros. Desde luego, los proyectos se multiplicaron, contemplando también la posibilidad de articular el istmo FitzcarraldCashpajali de $24 \mathrm{~km}$, accediendo directamente al río Mishagua y tal vez al Purús, territorio donde caucheros brasileños establecían las reglas de juego, en el comercio y la vida cotidiana.

6. Camino Souza-Vargas. Que comunicaba las quebradas de Sahuinto, tributario del Manu, con el Mishagua. Por esta ruta en 1908 se trasladó la primera lancha a vapor Madre de Dios -fabricada por H. Holtz en Hamburgode propiedad de la firma Souza-Vargas. Posteriormente, el cauchero Ricardo Hidalgo trasladó la lancha Inambari, embarcación construida en Francia, astilleros Berthen Freres-Sena, con capacidad para 15 toneladas.
7. Puerto Maldonado-Bajo Madre de Dios. Para acceder al río Beni y, utilizando los ferrocarriles primero de la Casa boliviana Suárez Hermanos, luego la ruta brasileña Madera-Mamoré, accedían al río Madeira y finalmente al Amazonas para salir al Atlántico.

8. Puerto Maldonado-Quincemil. A partir de la década de 1940, esta fue la última ruta a través del sistema modal aéreo terrestre y así llegar a Lima.

9. Tahuamanu-Acre e Iñapari-Acre. Con destino directo a los centros de acopio de $L a$ Empresa -hoy Río Branco-, luego a Manaos, Belem do Para, para finalmente enviar la mercadería a Nueva York o Liverpool. En este caso, el transporte era fluvial-marítimo.

10. Iberia-Quincemil-Lima. A partir de los años de 1940, ruta aérea y para el traslado de bolas de siringa; ocasionalmente y de manera ilícita, madera fina como caoba y cedro, particularmente en aviones oficiales.

Con la liquidación del Banco Agrario durante el gobierno de Fujimori-Montesinos, terminó el ciclo de las empresas cauchero-shiringueras, concluyendo esta época de la Amazonía, caracterizada no sólo por el movimiento de capitales, sino inclusive por una cultura extractiva. Hoy, un funcionario de Puerto Maldonado trata de vender ilusiones con un proyecto para reactivar la explotación de gomas elásticas; debe saber que Brasil, con todo el esfuerzo desplegado también para dicho propósito, no logra salir adelante más allá de la pequeña fábrica de camisinhas, en Xapuri. ¿A qué ciclo económico ingresará la Amazonía? 


\section{Bibliografía}

\section{ACUÑA, Cristóbal de}

[1640] 1942. Descubrimiento del Amazonas. Colección Buen Aire. Buenos Aires, Emecé Editores S.A

\section{AGN-Archivo General de la Nación.}

Sección Tierras de Montaña 1900-1925. 12. Lima.

\section{Ministerio de Relaciones Exteriores.}

21 de junio de 1911. AGN, Lima.

Carvajal, Gaspar de / P Arias de Almesto / A. de Rajas

2000. La Aventura del Amazonas. Madrid, Edición de Rafael Díaz Madernuelo. Crónicas de América, Dastin Historia.

\section{DELBOY, Emilio}

1936. Conferencia a los miembros de la Sociedad Geográfica de Lima. Las Regiones del Madre de Dios y Acre. SGL. Lima.

\section{FERNÁNDEZ MORO, Wenceslao O.P.}

1952. Cincuenta Años en la Amazonia. Madrid.

\section{FLORES MARÍN, José A.}

1977. La Explotación de Caucho en el Perí. Seminario de Historia Rural. (Mimeo. UNMSM)

\section{MAÚRTUA, Víctor $M$.}

1906 Juicio de límites entre el Pení y Bolivia, prueba peruana presentada al gobierno de la República de Argentina. $12 \mathrm{vol}$. Barcelona \& Madrid.

PACHACUTI YANQUi SALCAMAYGUA, Juan de Santa Cruz

[1613] 1993. Relación de Antiguiedades deste Reyno del Penú. Estudio etnohistórico y lingüístico de Pierre Duviols y César Itier. Cusco, IFE $\Lambda$-CBC.

\section{PAREDES PANDO, Óscar}

2011. Espacios étnicos, capital cauchero y fronteras nacionales: EI Alto Acre-Madre de Dios. 1576-2006. Sevilla, Tesis doctoral, UPO.

2009. "Manuena-Guariguaca: En los Antis de Opatari. La Amazonía Sur Oriental. Siglos XVI-XX". Vol. I. Cusco.

1992. Carretera interoceánica. Integración o marginación de la regrón Inka. Cusco, Centro Bartolomé de las Casas.

\section{PARSSINEN, Martti y Ari Siiriäinen}

2008. Andes orientales y Amazonía occidental. Ensayos entre la historia y la arqueologia de Bolivia, Brasil y Perí. La Paz, Producciones GIMA, Segunda Edición.

\section{PLAN DEL SUR}

"Plan de Desarrollo del Sur del Perú", vol. V PS/B/9. Los Recursos Humanos del Departamento de Puno. 1959, p. 45. Lima.

\section{STIGLICH, Germán}

1902. Informe del Fefe de la Comisión exploradora de las regiones del Ucavali, Fitzcarrald y Madre de Dios. Ültimas exploraciones ordenadas por la Junta de Vías Fluviales. Imp. "La Opinión Nacional" Lima.

\section{SUÁREZ C. Nicolás}

1928. Anotaciones y documentos sobre la campaña del Acre. Barcelona, Tip. La Academia.

\section{TIZÓN BUENO, A.}

1911. Informe sobre el camino Tirapata - Astillero. Lima, AGN / OPP. 